\title{
Vigilância Sanitária de estabelecimentos veterinários: uma área carente de legislação sanitária
}

\section{Sanitary Surveillance of veterinary facilities: an area in need of sanitary laws}

\author{
Flavio Fernando Batista \\ Moutinho*
}

Faculdade de Veterinária, Universidade Federal Fluminense/ Fundação Municipal de Saúde de Niterói, Niterói, RJ, Brasil

\section{* E-mail: flaviomoutinho@id.uff.br}

Recebido: 14 jul 2020

Aprovado: 19 jan 2021

\section{RESUMO}

Introdução: Estabelecimentos veterinários são aqueles onde são realizadas intervenções médico-veterinárias, sendo sujeitos às ações de vigilância sanitária. Objetivo: Discutir a carência de legislação sanitária incidente sobre esses estabelecimentos, buscando refletir sobre a importância da existência da mesma no contexto da Saúde Única. Método: Trata-se de estudo de análise documental em que foi selecionado e analisado um conjunto de documentos, com prioridade para os oriundos do Sistema Único de Saúde e do Sistema Nacional de Vigilância Sanitária. Resultados: As atividades desenvolvidas nos estabelecimentos veterinários envolvem riscos à saúde humana, animal e ambiental. Há carência de arcabouço jurídico, principalmente em nível federal, que dê suporte às ações da vigilância sanitária em relação a esses estabelecimentos, que sequer são considerados estabelecimentos de saúde, à luz do Ministério da Saúde. Conclusões: Tornam-se muito perceptíveis a carência e a necessidade de um arcabouço normativo em nível nacional que entenda e preveja esses estabelecimentos como estabelecimentos de saúde e normatize e homogeneíze as ações de vigilância sanitária realizadas em relação a eles. Além disso, entende-se que tais normas devam ser elaboradas sob a perspectiva da Saúde Única, visando contemplar tanto a saúde humana, como a ambiental e dos animais.

PALAVRAS-CHAVE: Vigilância Sanitária; Medicina Veterinária; Vigilância em Saúde; Legislação em Saúde

\begin{abstract}
Introduction: Veterinary facilities are those places were medical-veterinary procedures are performed. They are subject to sanitary surveillance actions. Objective: To discuss the lack of sanitary laws applicable to veterinary facilities, seeking to reflect upon the importance of such laws in the context of a Unified Health perspective. Method: This is a documental analysis study, whereby a set of documents has been selected and analyzed, particularly those arising from the Unified Health System and the National System of Sanitary Surveillance. Results: The activities carried out at veterinary facilities involve risks to the human health, animal health and environmental health. A legal framework, particularly at a federal level, is required to support the sanitary surveillance actions carried out at said facilities, which are not even regarded as health care centers according to the Ministry of Health. Conclusions: One can easily notice the lack and the need of a nationwide regulatory framework that understands and regards veterinary facilities as health care centers and that regulates and combines the sanitary surveillance actions performed thereat. Additionally, we understand that the mentioned said rules should be prepared under the Unified Health perspective, aiming at encompassing human health, environmental health and the animal health.
\end{abstract}

KEYWORDS: Sanitary Surveillance; Veterinary Medicine; Health Care Surveillance; Health Laws 


\section{INTRODUÇÃO}

$\mathrm{O}$ ato de cuidar dos animais sempre existiu ao longo da história da humanidade, como consta dos registros históricos mais antigos já encontrados. 0 profissional responsável por essa atividade recebeu diversos nomes no decorrer da história, como mariscal, mulomedicus, farrier, maréchal, albeytar, hipologista, alveitar e veterinário1. 0 termo veterinário, que acabou denominando a profissão até os dias atuais, teria sido usado pela primeira vez no século I d.C. pelo romano Lucio Columela para designar os pastores que curavam as enfermidades dos animais².

A ruptura epistemológica das práticas antigas de curar, que ocorriam inclusive no Brasil colonial, para a medicina veterinária, ocorreu com o iluminismo e a adoção dos princípios da racionalidade, quando da criação dos primeiros cursos superiores de medicina veterinária'. No Brasil, os primeiros surgiram tardiamente, somente no início do século XX, em Olinda, Pernambuco, e no Rio de Janeiro ${ }^{3}$.

Se, no início e na maior parte do tempo, a medicina veterinária se dedicou aos cavalos, por serem os animais mais importantes para a sociedade em tempos passados pela utilização para transporte e nas batalhas ${ }^{1,4}$, cada vez mais ela vem se especializando no atendimento dos animais de companhia, como cães, gatos e animais silvestres domesticados.

Diversas pesquisas mundo afora vêm demonstrando esses animais como membros da família, com as pessoas os enxergando como filhos, inserindo-os, inclusive, em rituais sociais, como festejos de aniversário. Outra situação que merece destaque são os processos que correm nas varas de família referentes à guarda de animais de companhia quando da separação de seus tutores. Assim, eles desempenham papéis significativos na vida das pessoas, invocando ética de cuidado e responsabilidade, que é um traço característico das relações familiares, sendo irrefutável o reconhecimento social da família multiespécie nas entidades familiares pós-modernas ${ }^{5}$.

Desde 1932, no governo Getúlio Vargas, o exercício da medicina veterinária é regulamentado no Brasil $^{6}$ e, desde 1993, a medicina veterinária é reconhecida no Brasil como uma profissão da área da saúde ${ }^{7}$. Mas os estabelecimentos veterinários, ainda que estejam no rol dos estabelecimentos fiscalizados pela Vigilância Sanitária, carecem de um arcabouço legal que possibilite uma atuação harmônica em nível nacional, principalmente em um contexto de Saúde Única, ou seja, com a inserção dos animais na dimensão que thes é devida, do ponto de vista epidemiológico e de relação com os humanos.

Pode-se entender Saúde Única como uma abordagem em que a saúde humana, a ambiental e a dos demais animais são consideradas de maneira integrada, já que são, por natureza, interligadas e indissociáveis ${ }^{8}$.

Tal normatização ganha ainda mais importância quando se considera que estudos vêm demonstrando o descumprimento de regras básicas de biossegurança $a^{9,10}$ e das normas da vigilância sanitária por parte dos estabelecimentos veterinários no Brasil ${ }^{11}$.

E nesse interim, é fundamental destacar a importância das zoonoses, enquanto doenças transmitidas entre os animais vertebrados e os humanos, no cenário sanitário vigente. Elas representam importante parcela no quantitativo das doenças infecciosas emergentes e reemergentes que vêm afetando os humanos nos últimos anos, retardando a transição epidemiológico-demográfica dos países emergentes como o Brasil. Além disso, elas podem ter drásticos efeitos econômicos e nos meios de subsistência a longo prazo ${ }^{12,13,14}$.

Desse modo, o presente trabalho teve como propósito discutir a carência de arcabouço legal federal, buscando refletir sobre a importância da existência dessas normas para estabelecimentos veterinários no contexto da Saúde Única.

\section{MÉTODO}

Trata-se de um trabalho baseado na metodologia da análise documental. Tal método consiste em uma primeira fase em que se deve providenciar a localização das fontes e a seleção dos documentos, e uma segunda fase, na qual as informações recolhidas devem ser tratadas e analisadas ${ }^{15}$. Sendo assim, foi selecionado um conjunto de documentos com informações sobre a questão a ser discutida, a saber, a carência de legislação sanitária acerca dos estabelecimentos veterinários, tomando-se como base os documentos oriundos do Sistema Único de Saúde (SUS) e seu Sistema Nacional de Vigilância Sanitária (SNVS), bem como do sistema formado pelo Conselho Federal de Medicina Veterinária (CFMV) e pelos Conselhos Regionais de Medicina Veterinária (CRMV).

Inicialmente foi efetuada uma consulta ao portal de legislação da Agência Nacional de Vigilância Sanitária - Anvisa (http://portal.anvisa.gov.br/legislacao\#/) a fim de identificar resoluções e portarias relacionadas aos serviços de saúde que contemplassem, formalmente excluíssem ou ignorassem os estabelecimentos veterinários.

Em seguida, fez-se uma busca nos sítios do CFMV e dos CRMV buscando normas e documentos que instrumentalizassem a discussão.

Por fim, foi feito um levantamento utilizando como bases de dados o Google Scholar e o Portal Regional da Biblioteca Virtual em Saúde (BVS). Foram utilizados os termos "vigilância sanitária” AND "estabelecimentos veterinários” e “legislação sanitária” AND “estabelecimentos veterinários”. Não foi estabelecido tempo de busca pois foi considerado que o assunto é pouco pesquisado.

No Portal Regional da BVS não foi obtido nenhum resultado com os termos buscados. No Google Scholar foram encontrados 91 resultados, mas somente um que abordava a questão da legislação sanitária propriamente dita. 
Com base nesses documentos-chave foi elaborada uma discussão sobre as fragilidades encontradas e a carência de legislação em âmbito nacional acerca do assunto, com foco na questão da Saúde Única.

\section{RESULTADOS E DISCUSSÃO}

Estabelecimentos veterinários são aqueles onde são realizadas intervenções médico-veterinárias ${ }^{16}$.

A Classificação Nacional de Atividades Econômicas (CNAE) visa à padronização das informações econômicas e ao controle tributário nas três esferas de governo, buscando melhorar a qualidade dos sistemas de informação que servem de base a decisões e ações do Poder Público. De acordo com a CNAE, todos os estabelecimentos veterinários (ambulatório, consultório, clínica, hospital, laboratório, e unidade de transporte veterinário) recebem o mesmo código: Atividades Veterinárias CNAE 7500-1/0017.

Segundo a Anvisa, as atividades veterinárias (CNAE 7500-1/00) estão classificadas como de risco dependente de informações, mas a norma classifica como risco alto aqueles estabelecimentos onde haja uso de medicamentos controlados, existência de equipamentos de diagnóstico por imagem e realização de procedimentos invasivos, por exemplo ${ }^{18}$. Em muitos estabelecimentos veterinários podem ser encontradas tais realidades.

De acordo com o Ministério da Saúde, os estabelecimentos veterinários não são enquadrados como estabelecimentos de saúde, já que estes englobariam somente aqueles onde são desenvolvidos ações e serviços de saúde humana ${ }^{19}$. Tal situação perdura ainda que, desde 2018, haja uma recomendação do Conselho Nacional de Saúde (CNS) para que estes estabelecimentos sejam enquadrados como estabelecimentos de saúde na normativa federal que regulamenta esses estabelecimentos, bem como sejam inseridos no Cadastro Nacional de Estabelecimentos de Saúde (CNES). 0 documento recomenda, ainda, que a Comissão Intergestores Tripartite (CIT) e a Anvisa regulamentem a situação dos estabelecimentos veterinários no âmbito do SNVS ${ }^{20}$.

Nesse sistema cabe à Anvisa, em âmbito nacional, normatizar o estabelecimento e funcionamento de serviços de interesse para a saúde, bem como regulamentar serviços que envolvam risco à saúde pública ${ }^{21}$.

Ainda assim, a Anvisa nunca estabeleceu normas para funcionamento de estabelecimentos veterinários. De acordo com a Agência, o papel da Vigilância Sanitária em relação a esses estabelecimentos não estaria pacificado em nível nacional havendo diferentes tipos de abordagens em diferentes entes federativos ${ }^{22}$.

De fato, a fiscalização de medicamentos de uso exclusivo veterinário, do ponto de vista legal é de competência exclusiva do Ministério da Agricultura, Pecuária e Abastecimento (MAPA) e das secretarias estaduais e distrital de agricultura ${ }^{22}$ e a fiscalização do exercício profissional cabe aos conselhos profissionais de medicina veterinária ${ }^{23}$.
Mas, de acordo com a Anvisa, a competência para a fiscalização da estrutura dos estabelecimentos veterinários caberia também a esses conselhos já que existe norma criada pelo CFMV com exigências mínimas para o funcionamento dos mesmos, podendo se realizar acordos, convênios ou legislações propondo soluções alternativas, de comum acordo entre as instituições, redefinindo papéis e atribuições e unificando a competência para a fiscalização desses estabelecimentos ${ }^{17}$.

O CFMV conceitua e estabelece condições de funcionamento, de acordo com a complexidade, dos diferentes tipos de estabelecimento de atendimento a pequenos animais de estimação, a saber: consultório, ambulatório, clínica e hospital veterinário. Dentre essas condições são elencadas os ambientes, estrutura física e equipamentos mínimos obrigatórios em cada tipo de estabelecimento. Além disso, prevê as boas práticas necessárias ao funcionamento dos estabelecimentos, envolvendo: as condições de armazenamento de medicamentos, vacinas, antígenos e outros materiais biológicos; as condições de armazenamento de alimentos para humanos e animais; o gerenciamento de resíduos; os fluxos de área suja e limpa, crítica e não crítica; o armazenamento e manejo escritural de medicamentos controlados de uso animal ou humano; as condições de conservação, segurança, organização, conforto e limpeza das instalações físicas, internas e externas; os materiais adequados de revestimento de mobiliários; os processos de desinfecção e esterilização de materiais e equipamentos; as ações de controle de vetores e animais sinantrópicos; o acondicionamento e o manejo de produtos vencidos, violados ou suspeitos de alteração ou adulteração'.

Cabe ressaltar que essa Resolução do CFMV não define e nem estabelece condições de funcionamento de outros estabelecimentos veterinários, como laboratórios, estabelecimentos de diagnóstico por imagem, bancos de sêmen e sangue e unidades de transporte veterinário.

Assim sendo, alguns CRMV vêm legislando acerca do assunto. O CRMV de São Paulo, por exemplo, normatizou os critérios para instalação e funcionamento de serviços médico-veterinários móveis (em veículos e containers) em ações programáticas, emergenciais ou sociais, sobre a qual o regulamento federal é omisso ${ }^{24}$. Já o CRMV do Rio de Janeiro criou uma resolução que trata do funcionamento e bom funcionamento dos estabelecimentos veterinários no estado, com exigências estruturais e documentais. A resolução salienta, inclusive, o seu objetivo de nortear as ações de vigilância sanitária por parte dos municípios, buscando isonomia na atuação dentro do estado ${ }^{25}$. Além disso, o CRMV-RJ normatizou por resolução a instalação e funcionamento dos chamados Serviços Veterinários Especializados no estado, os quais envolvem aqueles de diagnóstico por imagem, análises laboratoriais, bancos de sangue e bancos de sêmen ${ }^{26}$.

Em 2009, foi publicada uma referência técnica em cuja impressão vem grifado em letras grandes e em cor vermelha "sem valor legal" e cujo objetivo seria somente servir de orientação para os governos estaduais e municipais na implantação das ações de fiscalização dos serviços veterinários, caso ainda não a tivessem em funcionamento. As referências serviriam como sugestões e 
não como pré-condições e teriam como base a legislação vigente à época ${ }^{17}$.

De acordo com a referência técnica supracitada, em estabelecimentos veterinários, caberia à Vigilância Sanitária, principalmente, a atuação em relação aos aspectos sanitários legais que envolvam a prevenção de agravos e riscos à saúde humana. Isso englobaria o gerenciamento de resíduos, o abastecimento de água, a limpeza e higiene do local, a proteção ambiental, a saúde do trabalhador e as condições dos medicamentos da linha humana ${ }^{17}$.

A Anvisa traçou uma série de recomendações a serem observadas pelas Vigilância Sanitária licenciantes de estabelecimentos veterinários, como a exigência de alvará sanitária condizente com a área de atuação; questões referentes à radioproteção e à saúde do trabalhador (Programa de Prevenção de Riscos Ambientais - PPRA, Programa de Controle Médico e Saúde Ocupacional - PCMSO e cumprimento da NR-32, por exemplo); sobre as condições higiênico-sanitárias do estabelecimento, envolvendo o estado de conservação e limpeza do imóvel, dos móveis e equipamentos bem como alguns detalhamentos estruturais ${ }^{17}$.

Nesses detalhamentos estruturais foram incluídos: revestimento de teto, parede e pisos; exigência de mobiliário impermeável e íntegro; presença de lavatórios, dispensadores de sabonete líquido e papel toalha; lixeiras sem acionamento manual e com sacos plásticos; ambientes técnicos não servindo de acesso aos demais ambientes técnicos; ausência de ventiladores em áreas técnicas; obediência à legislação sobre funcionamento, manutenção e limpeza em ambientes providos de ar-condicionado; iluminação respeitando à legislação vigente; ralos sifonados e com tampas escamoteáveis; acesso exclusivo e independente quando existir comércio ou atividades de banho e estética animal concomitante aos serviços veterinários; elaboração de Procedimentos Operacionais Padrão (POP) contemplando as atividades executadas e à disposição de profissionais e fiscais sanitários; acessos cobertos a áreas técnicas e ambientes; características e periodicidade de limpeza dos reservatórios de água; e gerenciamento de resíduos. Em diversas situações, foi citada como referência para as recomendações nesse documento da Anvisa ${ }^{17}$ a Resolução da Diretoria Colegiada (RDC) da Anvisa $n^{\circ} 50$, de 22 de fevereiro de 2002.

A RDC Anvisa $n^{\circ}$ 50/2002 trata dos projetos físicos de assistência à saúde, e prevê que todos os estabelecimentos de assistência à saúde devem cumpri-la, mas em nenhum momento ela trata diretamente de estabelecimentos veterinários ${ }^{27}$. Todavia, se a legislação federal enfatiza que apesar de estarem sujeitos à ação da vigilância sanitária, os estabelecimentos de saúde animal não devem ser considerados estabelecimentos de saúde ${ }^{19}$, não há justificativa para a utilização dessa resolução para os estabelecimentos veterinários. Apesar disso, ela é citada na referência técnica da Anvisa para estabelecimentos veterinários ${ }^{17}$ e em diversas outras normas.

O CRMV de Minas Gerais, por exemplo, em seu Manual de Responsabilidade Técnica informa que os responsáveis técnicos por estabelecimentos veterinários devem fazê-los cumprir a legislação pertinente à área, referenciando, também dentre elas, a RDC Anvisa $\mathrm{n}^{\circ} 50 / 2002^{28}$.

A prefeitura de São Paulo também tem um regulamento técnico sobre as condições higiênico-sanitárias e as boas práticas em estabelecimentos veterinários, envolvendo as exigências mínimas das instalações, o uso de radiações, o uso de medicamentos, o controle de zoonoses e o funcionamento. Em seu Art. $2^{\circ}$, a Portaria da prefeitura de São Paulo deixa claro que as ações de vigilância em saúde tratam especialmente dos aspectos da saúde humana (trabalhadores, clientela e população), tendo como referência, mais uma vez, a RDC $n^{\circ}$ 50/2002 da Anvisa ${ }^{29}$.

No que diz respeito aos estabelecimentos veterinários que disponham de serviço de diagnóstico por imagem envolvendo radioatividade, a Anvisa orienta que seja requerida a prévia apresentação de projeto arquitetônico ao órgão municipal de Vigilância Sanitária, bem como o Projeto de Radioproteção. Estes estabelecimentos devem ter incluídos em seus alvarás de localização o código de serviço de diagnóstico por imagem com uso de radiação ionizante, exceto tomografia CNAE 8640-2/0517.

A Anvisa publicou, em 2019, a RDC n 330, de 20 de dezembro, que regulamenta esses serviços de radiologia, inclusive no que diz respeito ao controle das exposições ocupacionais e do público às tecnologias radiológicas ${ }^{30}$. Ao contrário da normativa anterior (Portaria $n^{\circ} 453$, de $1^{\circ}$ de junho de 1998), que também tratava do assunto, mas se restringia a fins médicos e odontológicos ${ }^{31}$ e foi revogada, esta inclui os serviços de radiologia veterinária (diagnóstica ou intervencionista) no rol de estabelecimentos que devem cumpri-la, mas deixando claro que o atendimento à norma deve ocorrer no que diz respeito à proteção à saúde dos trabalhadores e do público, sem qualquer tipo de menção aos pacientes animais ${ }^{30}$.

No que diz respeito ao uso de medicamentos, sabe-se que na medicina veterinária, principalmente na clínica de pequenos animais, são utilizados tanto medicamentos da linha humana, quanto medicamentos da linha veterinária, seja para tratamento ou para sedação e anestesia. De acordo com a Anvisa caberia à Vigilância Sanitária a fiscalização no que diz respeito à procedência, data de validade e condições de armazenamento e conservação bem como as exigências previstas na legislação de medicamentos e drogas de uso humano sujeitos a controle especial, como sala ou armário restrito e com chave, comprovantes de descarte e registros de movimentação. Apesar da competência dos órgãos de agricultura em relação à fiscalização dos medicamentos de uso exclusivo veterinário, a Anvisa recomenda a atuação da Vigilância Sanitária em relação ao mau acondicionamento e à validade dos produtos ${ }^{17}$.

O Ministério da Saúde dá competência às autoridades sanitárias de estados, municípios e ao Distrito Federal para a fiscalização da produção, comercialização e uso dos medicamentos controlados de uso humano, não havendo, portanto, dúvidas nessa área ${ }^{32}$. Mas, no que tange à questão da dispensação de medicamentos 
da linha humana em estabelecimentos veterinários, o entendimento não se encontra pacificado no país.

A Lei Federal $n^{\circ} 13.021$, de 8 de agosto de 2014, prevê que o funcionamento das farmácias de qualquer natureza requer, obrigatoriamente, a assistência e responsabilidade técnica de um farmacêutico habilitado ${ }^{33}$. As Vigilâncias Sanitárias de alguns entes federativos vêm cobrando essa presença nos estabelecimentos veterinários, mas no entendimento do CFMV tal exigência não tem cabimento já que os estabelecimentos veterinários já teriam obrigatoriedade de um médico veterinário como responsável técnico. Desse modo, essa situação vem gerando questionamentos por parte do CFMV e dos estabelecimentos na Anvisa e na justiça ${ }^{34,35}$.

Ainda nesse contexto, visando pacificar o entendimento, o CFMV criou uma resolução, em 2020, visando regulamentar as ações e serviços relacionados ao uso de produtos destinados ao uso em animais e delegando ao médico veterinário responsável técnico a responsabilização pela guarda, armazenamento, distribuição, prescrição, fracionamento, preparo, diluição, manipulação e uso desses produtos. Além disso, é prevista a exigência de local apropriado (acesso restrito, sem exposição ao público e ambiente trancado), de segregação e destino adequado aos produtos vencidos e da escrituração e controle desses produtos de acordo com as determinações da Vigilância Sanitária e do MAPA, de acordo com a natureza dos produtos ${ }^{36}$. Ainda assim, é necessário destacar a hierarquia das normas, em que uma resolução de conselho profissional, por ser uma norma infralegal não pode, em tese, contrariar uma lei federal, uma norma primária ${ }^{37}$.

Em relação ao gerenciamento de resíduos, a RDC Anvisa $\mathrm{n}^{\circ} 222$, de 28 de março de 2018, é bastante consistente e deixa muito clara a obrigatoriedade de cumprimento das exigências por parte dos estabelecimentos veterinários, já que ela se aplica a todos os geradores de resíduos de serviços de saúde, sem diferenciar esfera administrativa ou natureza, independentemente de se tratar ou não de um serviço de saúde, mas desde que gere resíduos similares aos gerados nesses estabelecimentos. A Resolução vai além e classifica como geradores de resíduos de serviços de saúde todos os serviços que desenvolvam atividades relacionadas com a atenção a saúde, seja humana ou animal ${ }^{38}$.

Apesar de a Anvisa regulamentar as boas práticas para o processamento de produtos para saúde, envolvendo os Centros de Material e Esterilização, mais uma vez, a norma exclui do escopo de aplicação da resolução os serviços de assistência veterinária ${ }^{39}$.

Alguns entes federativos vêm normatizando a respeito dos estabelecimentos veterinários. 0 estado de São Paulo possui, desde 1995, um Decreto que dispõe sobre as exigências mínimas para a instalação de estabelecimentos veterinários, envolvendo também o uso de radiações, de medicamentos, de trânsito de animais e o controle de zoonoses. Trata-se de uma norma abrangente que determina, por exemplo, os ambientes obrigatórios e suas dimensões mínimas, as condições e materiais utilizados no revestimento de pisos e paredes, os dispositivos para prevenção de animais sinantrópicos, os equipamentos de esterilização, os dispositivos para evitar ruídos e exalação de odores, dentre outros. O Decreto enfatiza a necessidade de que as instalações ofereçam higiene, conforto e segurança aos animais e às pessoas ${ }^{40}$.

Já no novo Código Sanitário do município do Rio de Janeiro existe uma classificação das atividades sujeitas à Vigilância Sanitária e os estabelecimentos veterinários, inclusive os de diagnóstico, classificados como "estabelecimentos de interesse da vigilância de zoonoses" (capítulo III) e não como "estabelecimentos de interesse da vigilância sanitária" (capítulo II), onde constam os estabelecimentos relacionados com a saúde humana. 0 referido código delega ao titular da subsecretaria responsável pelas ações de vigilância sanitária e controle de zoonoses a edição de regulamentos com as exigências previstas para cada tipo de estabelecimento, em face de suas particularidades ${ }^{41}$.

Quando, em 2018, o CNS recomendou o enquadramento dos estabelecimentos veterinários no rol dos estabelecimentos de saúde e sua normatização pela Anvisa, ele delineou muito bem um arrazoado que justifica tal inclusão, envolvendo o risco das zoonoses (inclusive o alto percentual que são de notificação obrigatória); o uso de radiações ionizantes, quimioterápicos, contrastes e medicamentos controlados da linha humana e o risco ambiental e ocupacional do uso de determinados tipos de medicamentos como os antineoplásicos que podem ocasionar neoplasias, mutação genética e má formação fetal ${ }^{20}$.

De acordo com a RDC Anvisa $\mathrm{n}^{\circ} 153$, de 26 de abril de 2017, todas as atividades econômicas de interesse sanitário devem ser objeto de gerenciamento de risco e aplicação de boas práticas sanitárias ${ }^{42}$, mas como cumprir tais exigências na ausência de uma legislação específica?

Cordeiro et al. ${ }^{43}$ relataram exatamente as dificuldades que podem surgir nas ações da vigilância sanitária tendo em vista a miríade de leis e normas existentes, as quais podem não contemplar todos os aspectos necessários, bem como em relação à possível contradição entre elas.

Além disso, é importante uma mudança de paradigma no SNVS no sentido de reconhecer a importância dos animais de companhia como partícipes do núcleo familiar, adequando às ações ao conceito de Saúde Única.

$\mathrm{Na}$ família multiespécie contemporânea, o que permeia a relação dos humanos com os demais animais não é mais o elemento patrimonial, mas sim o afeto, que possibilita essa união em torno de um núcleo, formando a família. Os animais de companhia, inclusive, já são reconhecidos como integrantes da família multiespécie no ordenamento jurídico nacional ${ }^{44}$. Eles passaram a funcionar na ordem simbólica da família, e nessa relação multiespécies, os humanos devem cuidar dos animais, contemplando suas reais necessidades ${ }^{45}$, já que essa configuração familiar envolve uma relação de proteção, confiança e bem-estar e, nesse contexto, os humanos, enquanto animais dotados de maior "racionalidade", devem se responsabilizar pela proteção dos interesses dos animais de companhia. Assim, o princípio da paternidade responsável, mutatis mutandis, pode ser aplicado no dever do cuidado entre guardiões e seus animais de companhia ${ }^{46}$. 
Pastori $^{47}$ afirma que os tutores buscam ampliar a vida de seus animais de companhia, dada a relação de afeto entre ambos, ainda que isso demande gastos significativos. Essa nova conformação e nova maneira de se relacionar por si só justificariam que a Vigilância Sanitária atuasse com a mesma visão em relação à proteção da vida humana e dos demais animais.

Mas numa abordagem de Saúde Única, que inclusive é proposta e incentivada pela Organização Mundial de Saúde, considera-se a inseparabilidade das saúdes ambiental, humana e dos demais animais, unificando os cuidados em saúde ${ }^{48}$. Nesse aspecto, Couto e Brandespim ${ }^{8}$ defenderam a importância de que as políticas de saúde pública devem se basear numa estrutura legal que contemple a perspectiva da Saúde Única. Tal aspecto ratificaria a necessidade da preocupação com a saúde dos animais na perspectiva da legislação da vigilância sanitária em relação aos estabelecimentos veterinários.

\section{CONCLUSÕES}

Em face do que foi apresentado e discutido, torna-se muito perceptível a carência de um arcabouço normativo de nível nacional que entenda e preveja os estabelecimentos veterinários como estabelecimentos de saúde e que normatize e homogenize as ações de vigilância sanitária realizadas pelos diferentes entes federativos em relação a eles, respeitando, obviamente, possíveis peculiaridades loco-regionais.

Além disso, entende-se que tal arcabouço normativo deve ser construído sob a perspectiva da Saúde Única, visando contemplar tanto a saúde humana, como a ambiental e dos animais. Não que os requisitos exigidos em estabelecimentos de saúde humana e animal devam ser os mesmos, mas que exista uma legislação sanitária federal que abarque também os estabelecimentos veterinários, resguardando suas peculiaridades, mas contemplando a todos, e protegendo a todos.

\section{REFERÊNCIAS}

1. Melo LEH, Magalhães FO, Almeida AV, Câmara CAG. De alveitares a veterinários: notas históricas sobre a medicina animal e a escola superior de medicina veterinária São Bento de Olinda, Pernambuco (1912-1926). Hist Cienc Saude Manguinhos. 2010;17(1):107-23. https://doi.org/10.1590/S0104-59702010000100007

2. Egaña CS. Historia de la medicina veterinaria española: albeiteria, mariscaleira, veterinaria. Madrid: Espasa Calpe; 1941.

3. Germiniani CLB. A história da medicina veterinária no Brasil. Arch Vet Science. 1998;3(1):1-8. https://doi.org/10.5380/avs.v3i1.3732

4. Garcia OR. Historia de la medicina veterinária. Redvet. 2019;10(5B):1-4.

5. Chaves M. Disputa de guarda de animais de companhia em sede de divórcio e dissolução de união estável: reconhecimento da família multiespécie? In: Pereira RC, Grisard Filho W, Burguer MLF, organizadores. Direito das famílias e sucessões: concurso de artigos. Belo Horizonte: Instituto Brasileiro de Direito de Família; 2017. p. 51-81.

6. Brasil. Decreto $\mathrm{N}^{\circ} 20.931$, de 11 de janeiro de 1932. Regula e fiscaliza o exercício da medicina, da odontologia, da medicina veterinária e das profissões de farmacêutico, parteira e enfermeira, no Brasil, e estabelece penas. Diário Oficial União. 15 jan 1932.

7. Brasil. Resolução $N^{\circ} 38$, de 4 de fevereiro de 1993. Modifica o artigo 14 , parágrafo $2^{\circ}$, do regimento interno do CNS, referente à presidência da reunião plenária do conselho. Diário Oficial União. 11 mar 1993

8. Couto RM, Brandespim DF. A review of the one health concept and its application as a tool for policy-makers. Int J One Health. 2020;6(1):83-9.

9. Valente D, Oliveira CAA, Rodrigues VC, Trebbi H. Condições de biossegurança em estabelecimentos de atendimento médico-veterinário no município de Ribeirão Preto, SP. Rev Educ Contin Med Vet Zootec. 2004;7(1/3):45-54. https://doi.org/10.36440/recmvz. v7i1/3.3237

10. Labarthe N, Pereira MEC. Biossegurança na experimentação e na clínica veterinária de pequenos animais. Cienc Vet Trop. 2008;11(Supl.1):153-7.

11. Moutinho FFB, Santos CS, Rocha MRD, Nunes VMA, Borges FVB, Farias Neto F. Caracterização das infrações sanitárias cometidas por estabelecimentos de serviços veterinários no município de Niterói, RJ (2014-2015). Med Vet (UFRPE). 2019;13(2):199-203. https://doi.org/10.26605/medvet-v13n2-3070

12. Grisotti $M$. Doenças infecciosas emergentes e a emergência das doenças: uma revisão conceitual e novas questões. Cienc Saude Coletiva. 2010;15(1):1095-104. https://doi.org/10.1590/ S1413-81232010000700017

13. Zanella JRC. Zoonoses emergentes and reemergentes e sua importância para a saúde e a produção animal. Pesq Agropec Bras. 2016;51(5):510-9. https://doi.org/10.1590/S0100-204X2016000500011

14. Food and Agriculture Organization of the United Nations - FAO. Adopción de un enfoque multisectorial una salud: guía tripartita para hacer frente a las enfermedades zoonóticas en los países. Rome: Food and Agriculture Organization of the United Nations; 2019[acesso 8 set 2020]. Disponível em: https://www.oie.int/es/para-los-periodistas/ una-sola-salud/control-de-los-riesgos-sanitarios/ colaboracion-nacional/

15. Calado SS, Ferreira SCR. Análise de documentos: método de recolha e análise de dados [monografia]. Lisboa: Universidade de Lisboa; 2005[acesso 4 mar 2020]. Disponível em: http://www.educ.fc.ul.pt/docentes/ ichagas/mi1/analisedocumentos.pdf 
16. Conselho Federal de Medicina Veterinária - CFMV. Resolução $N^{\circ} 1.275$, de 25 de junho de 2019. Conceitua e estabelece condições para o funcionamento de estabelecimentos médico veterinários de atendimento a animais de estimação de pequeno porte e dá outras providências. Diário Oficial União. 24 jul 2019.

17. Agência Nacional de Vigilância Sanitária - Anvisa. Referência técnica para o funcionamento de serviços veterinários. Brasília: Agência Nacional de Vigilância Sanitária; 2009.

18. Agência Nacional de Vigilância Sanitária - Anvisa. Instrução normativa № 16, de 26 de abril de 2017. Dispõe sobre a lista de classificação nacional de atividades econômicas CNAE classificadas por grau de risco para fins de licenciamento sanitário. Diário Oficial União. 27 abr 2017.

19. Ministério da Saúde (BR). Portaria $N^{\circ} 2.022$, de 7 de agosto de 2017. Altera o cadastro nacional de estabelecimentos de saúde (CNES), no que se refere à metodologia de cadastramento e atualização cadastral, no quesito tipo de estabelecimentos de saúde. Diário Oficial União. 15 ago 2017.

20. Brasil. Recomendação № 61, de 13 de dezembro de 2018. Recomenda aos tribunais brasileiros a implementação de programas de aprendizagem voltados à formação técnico-profissional metódica de adolescentes e jovens, a partir dos 14 anos, na forma dos artigos $\mathrm{N}^{\circ} 428$ a $\mathrm{N}^{\circ}$ 433 da consolidação das leis do trabalho CLT. Diário Oficial União. 14 dez 2018.

21. Brasil. Lei $N^{\circ} 9.782$, de 26 de janeiro de 1999. Define o Sistema Nacional de Vigilância Sanitária, cria a agência nacional de vigilância sanitária, e dá outras providências. Diário Oficial União. 27 jan 1999.

22. Brasil. Decreto $N^{\circ} 5.053$, de 22 de abril de 2004. Aprova o regulamento de fiscalização de produtos de uso veterinário e dos estabelecimentos que os fabriquem ou comerciem e dá outras providências. Diário Oficial União. 23 abr 2004.

23. Brasil. Lei $\mathrm{N}^{\circ} 5.517$, de 23 de outubro de 1968. Dispõe sobre o exercício da profissão de médico-veterinário e cria os conselhos federal e regionais de medicina veterinária. Diário Oficial União. 25 out 1968.

24. Conselho Regional de Medicina Veterinária de São Paulo - CRMV-SP. Resolução № 2.750, de 14 de março de 2018. Normatiza os critérios para instalações e condições de funcionamento dos serviços médico-veterinários móveis para cães e gatos no estado de São Paulo. Diário Oficial do Estado. 15 mar 2018.

25. Conselho Regional de Medicina Veterinária do Estado do Rio de Janeiro - CRMV-RJ. Resolução $N^{\circ} 27$, de 16 de maio de 2012. Dispõe sobre o funcionamento dos estabelecimentos médicos veterinários no âmbito do estado do Rio de Janeiro. Diário Oficial Estado. 17 maio 2012.

26. Conselho Regional de Medicina Veterinária do Estado do Rio de Janeiro - CRMV-RJ. Resolução $N^{\circ} 41$, de 1 de julho de 2014. Dispõe sobre a instalação e o funcionamento dos serviços de veterinária especializados no âmbito do estado do Rio de Janeiro. Diário Oficial União. 8 jul 2014.
27. Agência Nacional de Vigilância Sanitária - Anvisa. Resolução RDC № 50, de 21 de fevereiro de 2002. Dispõe sobre o regulamento técnico para planejamento, programação, elaboração e avaliação de projetos físicos de estabelecimentos assistenciais de saúde. Diário Oficial União. 22 fev 2002.

28. Conselho Regional de Medicina Veterinária do Estado de Minas Gerais - CRMV-MG. Resolução Nº 357, de 1 de março de 2016. Aprova normas de orientação técnico profissional para o exercício da responsabilidade técnica no estado de Minas Gerais. Diário Oficial Estado. 18 out 2017.

29. Prefeitura do Município de São Paulo. Portaria N ${ }^{\circ} 641$, de 8 de abril de 2016. Aprova o regulamento técnico sobre as condições higiênico-sanitárias e as boas práticas para estabelecimentos e serviços veterinários, determinando as exigências mínimas de instalações, de usos de radiações, de uso de drogas e do controle de zoonoses, bem como a adoção de boas práticas de funcionamento desses estabelecimentos. Diário Oficial do Município de São Paulo. 9 abr 2016.

30. Agência Nacional de Vigilância Sanitária - Anvisa. Resolução RDC No 330, de 20 de dezembro de 2019. Regulamenta as boas práticas de gerenciamento dos resíduos de serviços de saúde e dá outras providências. Diário Oficial União. 26 dez 2019.

31. Ministério da Saúde (BR). Portaria $N^{\circ} 453$, de 1 de junho de 1998. Aprova o regulamento técnico que estabelece as diretrizes básicas de proteção radiológica em radiodiagnóstico médico e odontológico, dispõe sobre o uso dos raios-x diagnósticos em todo território nacional e dá outras providências. Diário Oficial União. 2 jun 1998.

32. Ministério da Saúde (BR). Portaria $N^{\circ} 344$, de 12 de maio de 1998. Aprova o regulamento técnico sobre substâncias e medicamentos sujeitos a controle especial. Diário Oficial União. 13 maio 1998.

33. Brasil. Lei $\mathrm{N}^{\circ} 13.021$, de 8 de agosto de 2014. Dispõe sobre o exercício e a fiscalização das atividades farmacêuticas. Diário Oficial União. 9 ago 2014.

34. Conselho Federal de Medicina Veterinária - CFMV. CFMV solicita à Anvisa o fim da exigência da presença de farmacêuticos em estabelecimentos veterinários. Notícias. 27 set 2017[acesso 8 jul 2020]. Disponível em: http://portal.cfmv.gov.br/noticia/index/id/5330

35. Tribunal Regional Federal da $3^{\text {a }}$ Região - TRF-3. Agravo de instrumento $N^{\circ} 16999-47.2016 .4 .03 .0000 / S P$. Autuação de farmácia em clínica veterinária: medicamentos constantes da portaria № 344/1998: responsável técnico: necessidade. São Paulo: Tribunal Regional Federal da

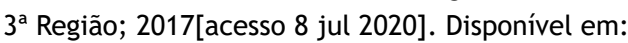
https://trf-3.jusbrasil.com.br/jurisprudencia/448932962/ agravo-de-instrumento-ai-169994720164030000-sp/ inteiro-teor-448932975

36. Conselho Federal de Medicina Veterinária - CFMV. Resolução № 1.318, de 6 de abril de 2020. Dispõe sobre o exercício das atividades relacionadas à assistência médico-veterinária que envolvam produtos para uso em animais e dá outras providências. Diário Oficial União. 7 abr 2020. 
37. Kelsen H. Teoria geral das normas. Porto Alegre: Fabris; 1986.

38. Agência Nacional de Vigilância Sanitária - Anvisa. Resolução RDC No 222, de 28 de março de 2018. Regulamenta as boas práticas de gerenciamento dos resíduos de serviços de saúde e dá outras providências. Diário Oficial União. 29 mar 2018.

39. Agência Nacional de Vigilância Sanitária - Anvisa. Resolução $\mathrm{RDC} \mathrm{N}^{\circ} 15$, de 15 de março de 2002. Dispõe sobre requisitos de boas práticas para o processamento de produtos para saúde e dá outras providências. Diário Oficial União. 16 mar 2002.

40. Governo do Estado de São Paulo. Decreto № 40.400, de 24 de outubro de 1995. Aprova norma técnica especial relativa à instalação de estabelecimentos veterinários. Diário Oficial União. 25 out 1995.

41. Prefeitura do Município do Rio de Janeiro. Decreto $N^{\circ} 45.585$, de 27 de dezembro de 2018. Dispõe sobre o regulamento administrativo do código de vigilância sanitária, vigilância de zoonoses e de inspeção agropecuária, de que trata a lei complementar $N^{\circ} 197$, de 27 de dezembro de 2018, no tocante ao licenciamento sanitário e aos procedimentos fiscalizatórios, e dá outras providências. Diário Oficial do Município do Rio de Janeiro. 28 dez 2018.

42. Agência Nacional de Vigilância Sanitária - Anvisa. Resolução RDC N 153, de 26 de abril de 2017. Dispõe sobre a classificação do grau de risco para as atividades econômicas sujeitas à vigilância sanitária, para fins de licenciamento, e dá outras providências. Diário Oficial União. 28 abr 2017.

43. Cordeiro RGF, Mello DR, Manso MEG, Nechio M, Carvalho W. Poder de polícia e as ações de vigilância sanitária. Integração. 2006;12(45):161-9.

44. Geissler ACJ, Pozzatti Junior A, Disconzi N. Fronteiras da bioética: os reflexos éticos e socioambientais. Caxias do Sul: Universidade Caxias do Sul; 2017.

45. Seguin E, Araújo LM, Cordeiro Neto MR. Uma nova família: a multiespécie. Rev Direito Ambient Socioambient. 2016;82:1-9.

46. Vieira TR, Cardin VSG. Antrozoologia e direito: o afeto como fundamento da família multiespécie. Rev Biodireito Direito Anim. 2017;3(1):127-41. https://doi.org/10.26668/ IndexLawJournals/2525-9695/2017.v3i1.3847

47. Pastori EO. Perto e longe do coração selvagem: um estudo antropológico sobre animais de estimação em Porto Alegre, RS [dissertação]. Porto Alegre: Universidade Federal do Rio Grande do Sul; 2012.

48. World Health Organization - WHO. Taking a multisectoral one health approach: a tripartite guide to addressing zoonotic diseases in countries. Genebra: World Health Organization; 2019[acesso 8 jul 2020]. Disponível em: www.oie.int/fileadmin/Home/eng/Media_Center/docs/ EN_TripartiteZoonosesGuide_webversion.pdf

Contribuição do Autor

Concepção, planejamento do estudo (desenho do estudo), aquisição, análise, interpretação dos dados e redação do manuscrito. 0 autor aprovou a versão final do trabalho.

Conflito de Interesse

Os autores informam não haver qualquer potencial conflito de interesse com pares e instituições, políticos ou financeiros deste estudo.

Licença CC BY-NC atribuição não comercial. Com essa licença é permitido acessar, baixar (download), copiar, imprimir, compartilhar, reutilizar e distribuir os artigos, desde que para uso não comercial e com a citação da fonte, conferindo os devidos créditos de autoria e menção à Visa em Debate. Nesses casos, nenhuma permissão é necessária por parte dos autores ou dos editores. 